Research Article

\title{
Transportation Laws for Carbonate and Sulfate Ions in Concrete Based on Compartment Model
}

\author{
Boxin Wang (D), Ruichang Fang, Xu Chai, and Qing Wang \\ College of Construction Engineering, Jilin University, Changchun 130021, Jilin, China \\ Correspondence should be addressed to Boxin Wang; boxinwang@jlu.edu.cn
}

Received 6 February 2020; Revised 29 June 2020; Accepted 8 July 2020; Published 23 July 2020

Academic Editor: Valeria Vignali

Copyright (C) 2020 Boxin Wang et al. This is an open access article distributed under the Creative Commons Attribution License, which permits unrestricted use, distribution, and reproduction in any medium, provided the original work is properly cited.

Transportation of carbonate and sulfate ions in concrete under the drying-wetting cycle environment is similar to the ingression and elimination of medicine in human body. Given this similarity, such a process is described dynamically using the classic compartment model in pharmacokinetics. The compartment model was applied to predict the content of carbonate and sulfate ions in different regions of concrete. Factors such as water-cement ratio, salt category, carbonate-ion and sulfate-ion attack depth, and drying-wetting cycle were synthetically considered in the compartment model. In conjunction with the prediction value of the compartment model, the experiment data uniformly distributed two sides of the model curve, and the difference is within the accepted range, thus verifying the reliability of the model prediction consequence. The compartment model in this article provides references for predicting the drying-wetting varied cycles and ions attack depth of concrete under carbonate and sulfate ions attack.

\section{Introduction}

The western region of Jilin Province is not only one of the three largest carbonate salinized soil regions worldwide but also the largest carbonate salinized soil region in China. The salinized soil considerably damages the local concrete structures. Degradation of local buildings increases rapidly due to the coupling action of saline soil and drying-wetting climate cycle, greatly shortening the service life and durability of concrete structure. In this article, as shown in Figure 1, Da'an, Nong'an, and Zhenlai in western Jilin Province were selected for practical engineering environment to research the influence the coupling action of ions attack and drying-wetting cycles on the durability of structure and investigate the transportation laws of carbonate and sulfate ions in concrete.

To date, many theoretical methods have been used to describe the transportation of ions in concrete, such as Fick's second Law, which has been employed by Vera et al. [1], Jin et al. [2, 3], Zhou et al. [4, 5], He et al. [6], Zhang et al. [7], and $\mathrm{Hu}$ et al. [8]. The dual porous medium model had been carried out by Yan et al. $[9,10]$. The multiscale model and composite sphere model had been used by Liu et al. [11], Sun et al. [12-14], and Gao et al. [15]. Kari et al. [16] and Lin et al. [17] simulated the transportation behavior through the software PHREEQC. Bary et al. [18] developed and applied a chemo-transport-mechanical model for simulating the external sulfate attack in Portland cement pastes and mortars. The cellular automaton (CA) model had been adopted by Cao et al. [19] to imitate the transportation behavior. Zhang et al. [20] established a one-dimensional mathematical coupled model of hydraulic-thermal-salt and modeled moisture migration and salt transport by numerical simulation.

To describe the transportation behavior of ions in concrete during the immersion stage, Fick's second law was adopted by many scholars. Rich achievement has been acquired after employing this law. However, adopting Fick's second law in a changing outside environment is inadvisable. The concentration gradient will change when the concentration of pore solution varies, and the coefficient of permeability will change accordingly. Fick's second law cannot dynamically and accurately describe this process. In addition, when defined in the immersion 


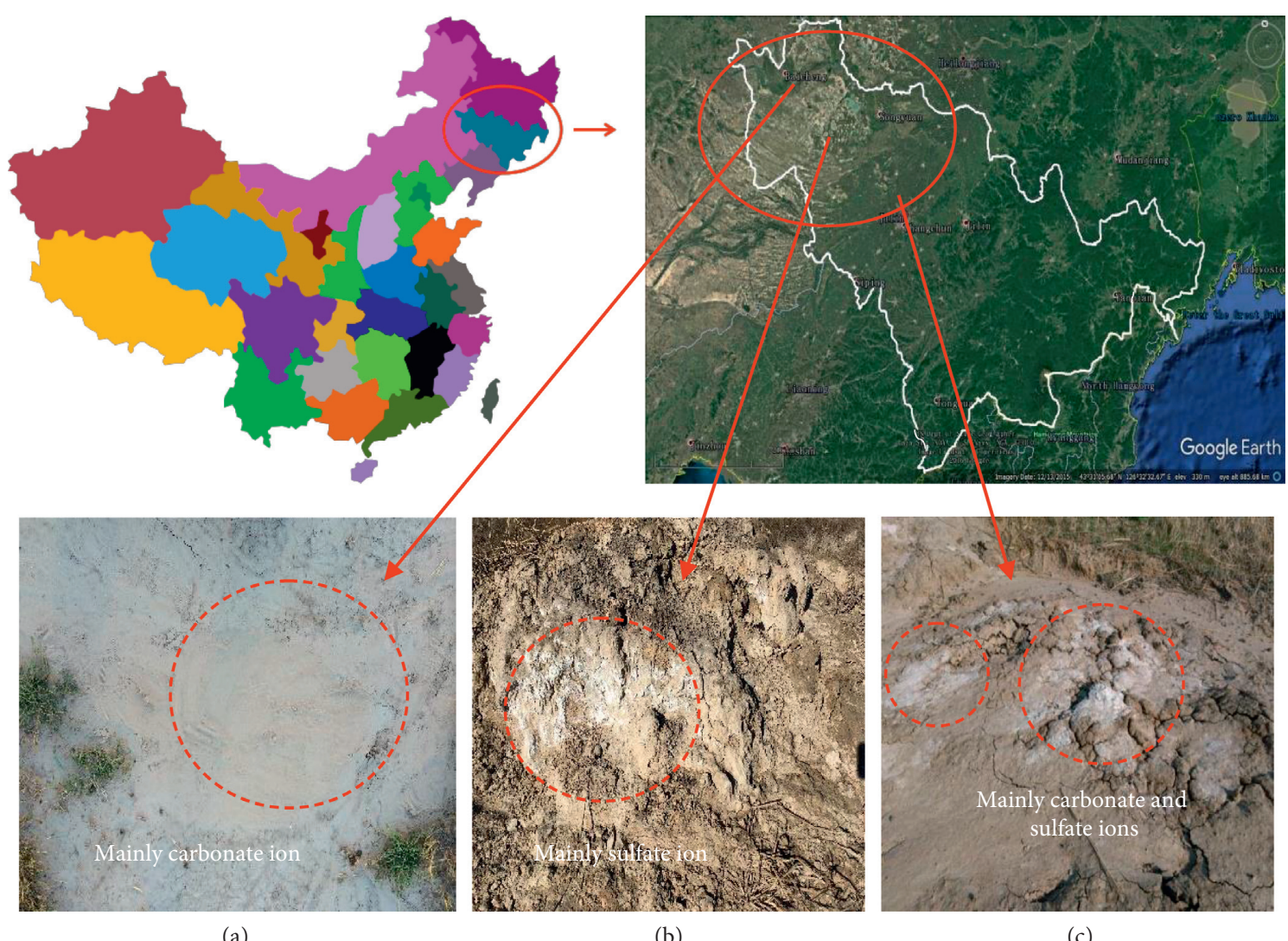

(a)

(b)

(c)

Figure 1: (a) Research environment (saline soil) in Zhenlai, (b) Da'an, and (c) Nong'an.

stage, saline soil covers the concrete or immerses in the pore solution followed by the dehydration stage (ion elimination process) in which the concrete emerges from solution or exposes to air when the environment outside changes due to thee drying-wetting cycle. Fick's second law can only describe the immersion stage. The dehydration stage (ion elimination process) cannot be described accurately.

Drying-wetting cycles provide dynamic foundation for carbonate and sulfate ions ingression and elimination in concrete. When the transportation of ions in concrete is compared with the ingression and elimination of medicine in human body, results infer that both processes are under specific dynamic foundation and exhibit ingression and elimination during transportation. Therefore, the classic compartment model in pharmacokinetics is brought in to dynamically describe the transportation of carbonate and sulfate ions in concrete under the dryingwetting cycle environment. The compartment model can improve the incapability of Fick's second law to describe the dehydration stage (ion elimination process), carbonate and sulfate ion ingression, and elimination in concrete under the action of drying-wetting cycle environment. The chamber model is more suitable to describe the migration law of $\mathrm{CO}_{3}^{-2}$ and $\mathrm{SO}_{4}^{2-}$ in concrete under the dry-wet cycle mechanism. According to the precision requirements of ion concentration in concrete, the internal area of concrete can be divided into several chambers according to certain rules. The dynamic foundation of the external system ensures the ion flow in and out of each chamber and exchange. Between the two, the compartment model is a more appropriate method to dynamically describe the carbonate and sulfate ion transportation in concrete.

\section{Compartment Model}

\subsection{Model Assumptions}

(1) Effect of microcracks' self-healing ability in concrete is not considered

(2) How water influences pores in concrete and microcrack structure is not considered

(3) The volume of pores in different compartment remains steady during the drying-wetting cycles

(4) In the behavior of ingression and elimination from salt solution to convective area and from convective area to diffusion area, the rate of transfer is proportional to the concentration of the solution

2.2. Determination of Compartment Number and Demarcation among Different Regions. In conjunction with dealing with carbonate and sulfate ions content-concrete erosion stage, the number of compartments can be preliminarily determined. Three certifications of determining the number of compartments are available [21], and one of them is based on residual sum of squares $\left(R_{e}\right)$ : 


$$
R_{e}=\sum_{i=1}^{n}\left(c_{i}-\hat{c}_{i}\right)^{2}
$$

where $c_{i}$ means the experiment data of ion content and $\hat{c}_{i}$ means the fitting ion content.

Another certification is the degree of fitting $\left(r^{2}\right)$ :

$$
r^{2}=\frac{\sum_{i=1}^{n} c_{i}^{2}-\sum_{i=1}^{n}\left(c_{i}-\hat{c}_{i}\right)^{2}}{\sum_{i=1}^{n} c_{i}^{2}}
$$

Finally, Akaike's Information Criterion (AIC) value is the most used certification to determine the number of compartments:

$$
A I C=N \ln R_{e}+2 P .
$$

where $N$ means the number of experiment data, $P$ means number of parameters in the selected model, and $R_{e}$ means residual sum of squares.

According to this certification, the calculated parameter provides enhanced accuracy as AIC value is the least when different methods are selected to fit the curve for similar model. The compartment model can avoid overfitting effectively and limit the use of complex function. Using more than three compartments for practice is inappropriate.

To determine the number of compartment and divide concrete into different regions properly, the employment of analysis and consequence comparison of carbonate and sulfate ion content-concrete attack stages was necessary, followed by the calculation of AIC value. The result indicates that when the concrete is converged into one compartment, the phenomenon of the carbonate-ion content and sulfateion content rapidly declining in concrete cannot be described and explained accurately. Likewise, dividing the concrete into three different compartments can lead to the overfitting of curve. Considering this finding, two compartments can accurately describe ion transportation in concrete and meet the requirements of precise calculation precision.

Recommendation from engineering project Dura Crete [22] in Europe provides reference to divide concrete into proper compartments, suggesting that the concrete can be divided into regions of convection and diffusion and two compartments correspondingly. Figure 2 shows that the drying-wetting cycle region of concrete is divided into convection region, whose depth is $\Delta x$, and diffusion region, whose depth is $l-\Delta x$.

According to the carbonate-ion and sulfate-ion attack depth experiment, after 180 days of drying-wetting cycle, the ions attack depth became limited. The ion content reached almost 0 at $20 \mathrm{~mm}$ attack depth, and the ion content declined rapidly at $5 \mathrm{~mm}$ attack depth. The length of convection region was nearly $1 / 5 \sim 1 / 4$ the depth of the concrete protective layer. The carbonate-ion and sulfate-ion attack depth curve matches well with the conclusions presented in research on ion attack depth in concrete [16, 18, 23-25]. Therefore, the average convection region ion content ranges from 0 to $5 \mathrm{~mm}$, and the average diffusion region ion content ranges from $5 \mathrm{~mm}$ to $20 \mathrm{~mm}$.
Comprehensively considering the calculation of $A I C$ value and the recommendation of engineering project Dura Crete in Europe, a two-compartment model was adopted to describe the ion transportation in concrete.

2.3. Establishment of Model. Drying-wetting cycle condition provides dynamic foundation for carbonate and sulfate ions ingression and elimination in concrete. When defined in the immersion stage, the concrete immerses into the salt solution stage (elimination stage) and then the concrete emerges from salt solution or exposes to air.

Based on the model assumptions, a two-compartment model can be established.

$x_{i}(t)$ means the mass of solute at $t$ moment, $i=1,2, x_{i}^{\prime}(t)$ means the gradient mass of solute, $i=1,2, k_{i j}$ means the transfer rate from compartment $i$ to compartment $j$, and $f_{0}(t)$ means attack rate.

$k_{12} x_{1}$ means the transfer rate from compartment 1 to compartment $2, k_{21} x_{2}$ means the transfer rate from compartment 2 to compartment 1 , and $k_{13} x_{1}$ means the transfer rate from compartment 1 to solution outside. The gradient of $x_{1}(t)$ is composed of $k_{12} x_{1}, k_{21} x_{2}, k_{13} x_{1}$, and $f_{0}(t)$. The gradient of $x_{1}(t)$ is composed of $k_{12} x_{1}$ and $k_{21} x_{2}$.

The following equation can be acquired according to the model assumptions [25]:

$$
\left\{\begin{array}{l}
x_{1}^{\prime}(t)=-k_{12} x_{1}-k_{13} x_{1}+k_{21} x_{2}+f_{0}(t), \\
x_{2}^{\prime}(t)=k_{12} x_{1}-k_{21} x_{2} .
\end{array}\right.
$$

The relationship among $x_{i}(t), c_{i}(t)$, which is the concentration of compartment, and $V_{i}(i=1,2)$, which is the volume of compartment, is expressed as follows:

$$
x_{i}(t)=V_{i} c_{i}(t), \quad i=1,2 .
$$

If we substitute equation (5) into equation (4), then we can acquire the following equation:

$$
\left\{\begin{array}{l}
c_{1}^{\prime}(t)=-\left(k_{12}+k_{13}\right) c_{1}+\frac{V_{2}}{V_{1}} k_{21} c_{2}+\frac{f_{0}(t)}{V_{1}}, \\
c_{2}^{\prime}(t)=\frac{V_{1}}{V_{2}} k_{12} c_{1}-k_{21} c_{2},
\end{array}\right.
$$

where $c_{i}^{\prime}(t)$ means the gradient of ion concentration; in the equation, $i=1,2$.

2.4. Solution of Model. The solution of linear differential equation with constant coefficients comprises the general solution of homogeneous equation and the special solution of inhomogeneous equation. The general solution of linear homogeneous system of equations is expressed as follows:

$$
\left\{\begin{array}{l}
\bar{c}_{1}(t)=A_{1} e^{-\alpha t}+B_{1} e^{-\beta t}, \\
\bar{c}_{2}(t)=A_{2} e^{-\alpha t}+B_{2} e^{-\beta t} .
\end{array}\right.
$$

where $\alpha$ and $\beta$ can be determined by 

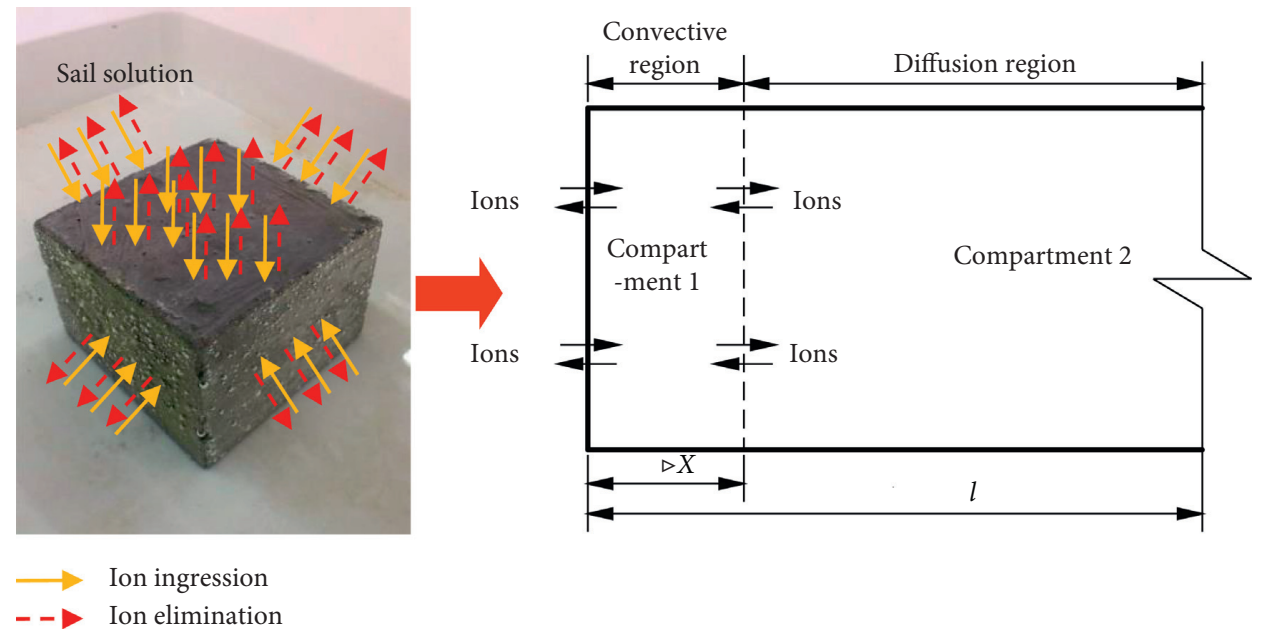

Figure 2: Ion transportation under the drying-wetting cycle (entity figure and simplified model schematic).

$$
\left\{\begin{array}{l}
\alpha+\beta=k_{12}+k_{21}+k_{13}, \\
\alpha \beta=k_{21} k_{13} .
\end{array}\right.
$$

To acquire the special solution of inhomogeneous equation and solve equation (6), we set $f_{0}(t)$ and initial condition.

The volume in which salt solution ingresses into concrete holes in comparison with the volume of salt solution can be ignored, so we regarded ion initial concentration as constant. We accepted that the transfer rate is constant $k_{0}$. Accordingly, the initial condition can be written as follows:

$$
\begin{aligned}
& f_{0}(t)=k_{0}, \\
& c_{1}(0)=0, \\
& c_{2}(0)=0 .
\end{aligned}
$$

Combining the initial condition of equation (9), the solution of equation (6) can be acquired as follows:

$$
\left\{\begin{array}{l}
c_{1}(t)=A_{1} e^{-\alpha t}+B_{1} e^{-\beta t}+\frac{k_{0}}{k_{13} V_{1}}, \\
c_{2}(t)=A_{2} e^{-\alpha t}+B_{2} e^{-\beta t}+\frac{k_{12} k_{0}}{k_{21} k_{13} V_{2}} \\
A_{2}=\frac{V_{1}\left(k_{12}+k_{13}-\alpha\right)}{k_{21} V_{2}} A_{1} \\
B_{2}=\frac{V_{1}\left(k_{12}+k_{13}-\beta\right)}{k_{21} V_{2}} B_{1} .
\end{array}\right.
$$

Equation (10) presents the proposed two-compartment model that can describe the ion content in distinct regions of concrete at different attack ages.

\section{Experiment}

3.1. Experiment Material and Mix Proportion. Cement: 42.5 ordinary Portland cement.
Sand: river-sand with an average fineness modulus of 2.4 2.9.

Stone: limestone gravel with particle size of $5 \mathrm{~mm} \sim 10 \mathrm{~mm}$.

Water: distilled water.

Water-reducing admixture: Sika III produced by SIKA Corporation.

The mix proportions of concrete are listed in Table 1.

3.2. Design for One-Dimensional Ion Attack Coating System. The scale of specimen was $100 \mathrm{~mm} \times 100 \mathrm{~mm} \times 100 \mathrm{~mm}$. The average compressive strength of two kinds of concrete cube specimens was $36.08 \mathrm{MPa}$ (mixture $A$ ) and $45.14 \mathrm{MPa}$ (mixture $B$ ) according to standard ASTM C39 (Standard Test Method for Compressive Strength of Cylindrical Concrete Specimens) after the water curing of 28 days. The concrete specimen was designed to suffer one-dimensional ion attack to avoid the influence of gravity on ion transportation and the coupling action at the corner of specimen by two-dimensional ion attack. The concrete specimens were designed to wear the coating system to achieve one-dimension carbonate and sulfate ion transportation in concrete, as shown in Figure 3.

Firstly, the epoxy resin glue was put on the four adjacent sides of specimen surface. Secondly, the epoxy resin glue was covered with plastic wrap. Finally, the specimen was put near electric baking fan for the epoxy resin glue to solidify faster.

3.3. Preparation for Sodium Carbonate and Sodium Sulfate Solution. Table 2 shows the major salt in the saline soil in western Jilin province and the solubility at $20^{\circ} \mathrm{C}$. A sizable amount of carbonate and sulfate ions was found on the sampling from the experiment spot. To ensure similarity of the ions attack result to real pore solution concentration in salinized soil region and consider the solubility of the solute selected, 5\% sodium carbonate and sodium sulfate solution were prepared, respectively. The selection of concentration of $5 \%$ of exposure solution is also recently reported elsewhere among durability studies [26, 27]. 
TABLE 1: Mix proportions of concrete $\left(\mathrm{kg} / \mathrm{m}^{3}\right)$.

\begin{tabular}{lccccc}
\hline Mixture ID, water cement ratio & Water & Cement & Sand & Gravel & Superplasticizer \\
\hline A 0.45 & 185 & 411 & 545 & 1158 & 3.2 \\
$B \quad 0.55$ & 185 & 337 & 633 & 1125 & 3.6 \\
\hline
\end{tabular}

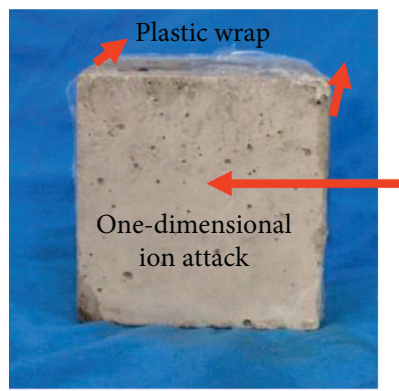

(a)

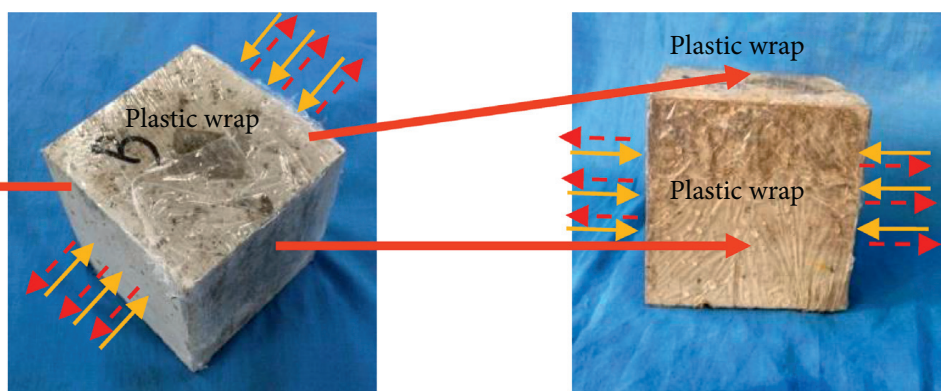

(b)

(c) $\begin{array}{ll}\longrightarrow & \text { Ion ingression } \\ -\rightarrow & \text { Ion elimination }\end{array}$

Figure 3: One-dimension ion attack coating system. (a) One-dimension. (b) Vertical view ion attack sides. (c) Coating system of specimen 2 .

Table 2: Detection and sampling results in the western Jilin Province.

\begin{tabular}{lccr}
\hline Ion & Content in soil $(\mathrm{g} / \mathrm{kg})$ & Concentration in pore solution $(\%)$ & Solubility at $20^{\circ} \mathrm{C}(\mathrm{g} / 100 \mathrm{~mL}$ water $)$ \\
\hline $\mathrm{SO}_{4}{ }^{2-}$ & 1.58 & $2.4 \sim 4.3$ & 19.5 \\
$\mathrm{CO}_{3}^{-2}$ & 0.97 & $3.1 \sim 4.7$ & 20.0 \\
\hline
\end{tabular}

3.4. Experiment Procedure. We selected the method provided in the ASTM C1894-19 Standard Guide for Microbially Induced Corrosion of Concrete Products [28], after comprehensively comparing the test methods used in the literature [29]. Drying-wetting cycle mechanism during experiment is shown as Figure 4.

Firstly, the specimens were soaked in the salt solution for $15 \mathrm{~h}$. Secondly, the specimens were taken out of solution and ventilated for $1 \mathrm{~h}$. Thirdly, the specimens were dried for $6 \mathrm{~h}$ at $60^{\circ} \mathrm{C}\left( \pm 2^{\circ} \mathrm{C}\right)$. Finally, the specimens were ventilated for $1 \mathrm{~h}$. All procedures above made up one cycle. The ion content in concrete was tested at 20,40,60,80,100,120,140,160, and 180 days. The pores and the microstructure in concrete were also observed by SEM [30] at the end of the experiment (180 days). The experiment procedure of ion content test in concrete is shown as Figure 5.

Firstly, we dealt with the concrete at different cycles with cutting machine according to varied carbonate ion and sulfate ion attack depth and then placed the concrete slide under the press machine and grinded little concrete block in the mortar. Following this, we selected the concrete powder picked from the $0.08 \mathrm{~mm}$ griddle. Secondly, we took $5 \mathrm{~g}$ concrete powder by using an electric balance with a precision of $0.1 \mathrm{mg}$, added in $100 \mathrm{~mL}$ distilled water and $10 \mathrm{~mL} 1: 1$ hydrochloric acid solution, shook sufficiently, and allowed ions to dissolve adequately by warm water bath. Thirdly, we added $10 \mathrm{~mL}$ $10 \%$ barium chloride solution according to the barium sulfate gravimetric method, collected precipitate and put it in $800^{\circ} \mathrm{C}$ high temperature stove, and weighed the mass of precipitate after completely cooled. Finally, we calculated the ion content using the equation in the barium sulfate gravimetric method (precision requirement is $0.01 \%)$.

3.5. Experiment Result. According to the aforementioned experiment procedures, we tested the carbonate ion content and sulfate ion content in different attack depths of concrete every 20 days until we reached a total of 180 days. Figure 6 shows the relationship between the test results of ion content in different attack depths of concrete and varied dryingwetting cycles.

\section{Model Evaluation and Result Analysis}

The laws for ion content development in the convection and diffusion regions of concrete with water-cement ratios of 0.45 and 0.55 that suffered from the attack of sodium carbonate whose concentration is $5000 \mathrm{mg} / \mathrm{L}$ are as follows: 


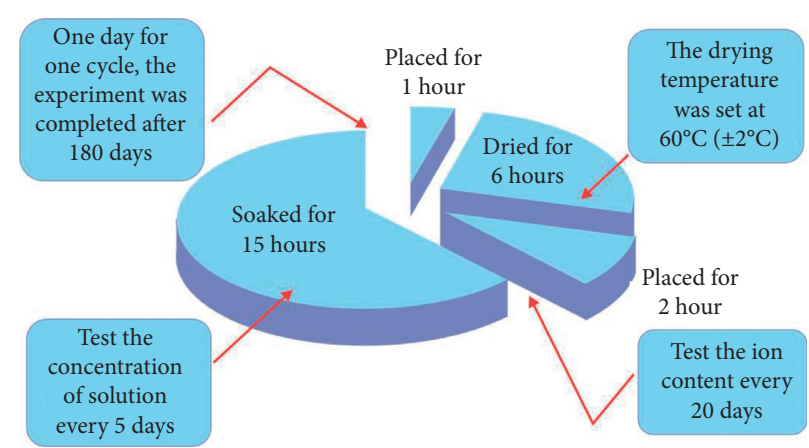

FIGURE 4: Drying-wetting cycle mechanism during experiment.

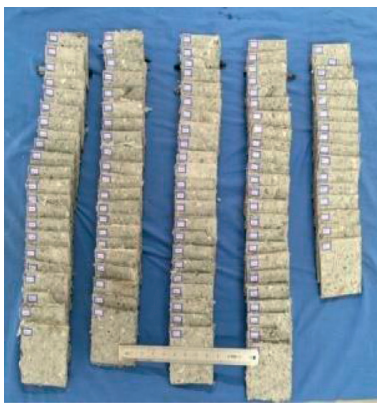

(a)

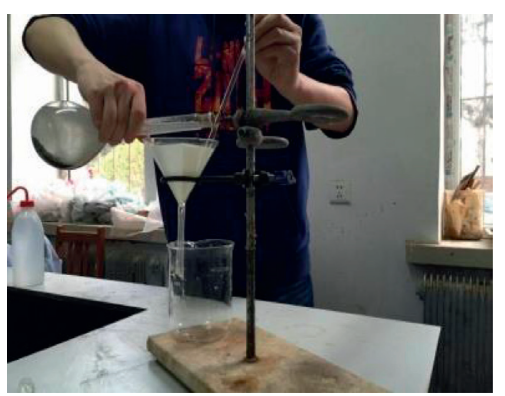

(e)

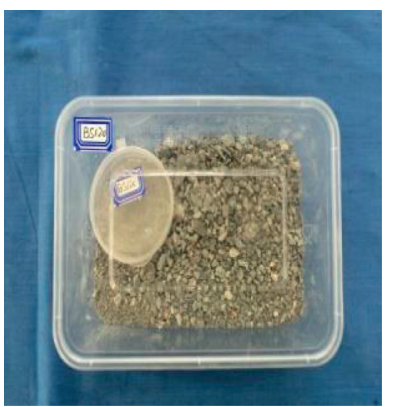

(b)

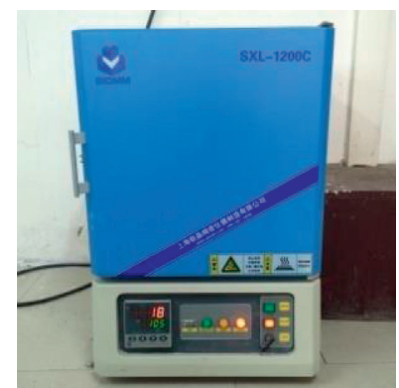

(f)

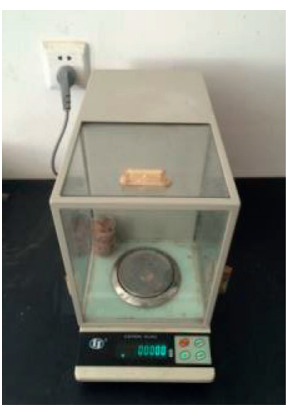

(c)

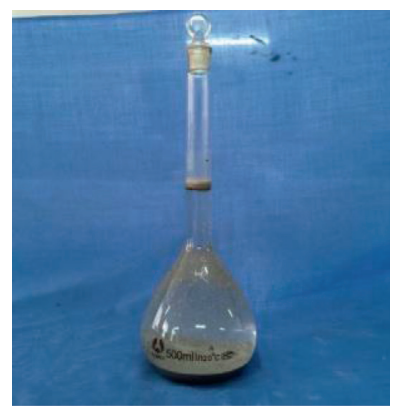

(d)

FIGURE 5: Experiment procedures of sulfate ion content test in concrete. (a) Cut. (b) Collected powder. (c) Weighing of powder. (d) Extraction. (e) Collection of precipitate. (f) High-temperature stove. (g) Weighing of the precipitate.

$$
\begin{aligned}
& \left\{\begin{array}{l}
c_{1}(t)=6.397 \times 10^{-3} \times e^{6.554 \times 10^{-3} t}+4.891 \times 10^{-4} \times e^{-8.868 \times 10^{-3} t}-6.881 \times 10^{-3}, \\
c_{2}(t)=3.102 \times 10^{-3} \times e^{6.554 \times 10^{-3} t}-2.294 \times 10^{-3} \times e^{-8.868 \times 10^{-3} t}-2.397 \times 10^{-3},
\end{array}\right. \\
& \left\{\begin{array}{l}
c_{1}(t)=8.338 \times 10^{-3} \times e^{5.537 \times 10^{-3} t}+2.688 \times 10^{-3} \times e^{-6.431 \times 10^{-3} t}-1.753 \times 10^{-3}, \\
c_{2}(t)=2.856 \times 10^{-3} \times e^{5.537 \times 10^{-3} t}-8.998 \times 10^{-3} \times e^{-6.431 \times 10^{-3} t}+4.323 \times 10^{-3}
\end{array}\right.
\end{aligned}
$$

The laws for ion content development in the convection and diffusion regions of concrete with water-cement ratios of 0.45 and 0.55 that suffered from the attack of sodium sulfate whose concentration is $5000 \mathrm{mg} / \mathrm{L}$ are as follows:

$$
\begin{aligned}
& \left\{\begin{array}{l}
c_{1}(t)=6.078 \times 10^{-3} \times e^{6.672 \times 10^{-3} t}+3.406 \times 10^{-4} \times e^{4.561 \times 10^{-3} t}-7.732 \times 10^{-4}, \\
c_{2}(t)=2.487 \times 10^{-3} \times e^{6.672 \times 10^{-3} t}-1.554 \times 10^{-3} \times e^{4.561 \times 10^{-3} t}-2.271 \times 10^{-3},
\end{array}\right. \\
& \left\{\begin{array}{l}
c_{1}(t)=6.543 \times 10^{-3} \times e^{6.753 \times 10^{-3} t}+2.865 \times 10^{-4} \times e^{2.812 \times 10^{-3} t}-4.785 \times 10^{-4}, \\
c_{2}(t)=1.926 \times 10^{-3} \times e^{6.753 \times 10^{-3} t}-7.532 \times 10^{-4} \times e^{2.812 \times 10^{-3} t}-1.126 \times 10^{-4}
\end{array}\right.
\end{aligned}
$$




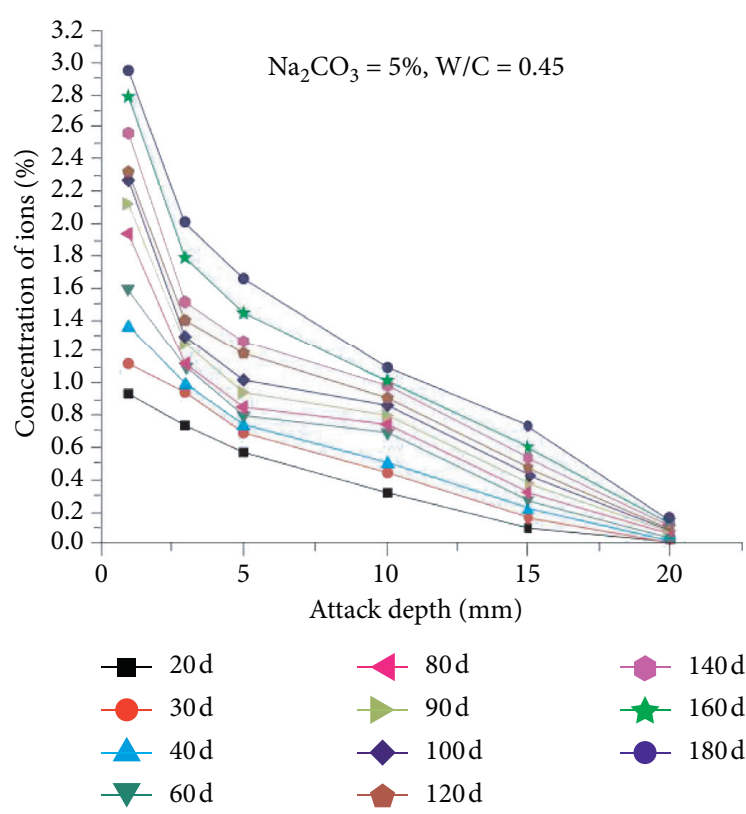

(a)

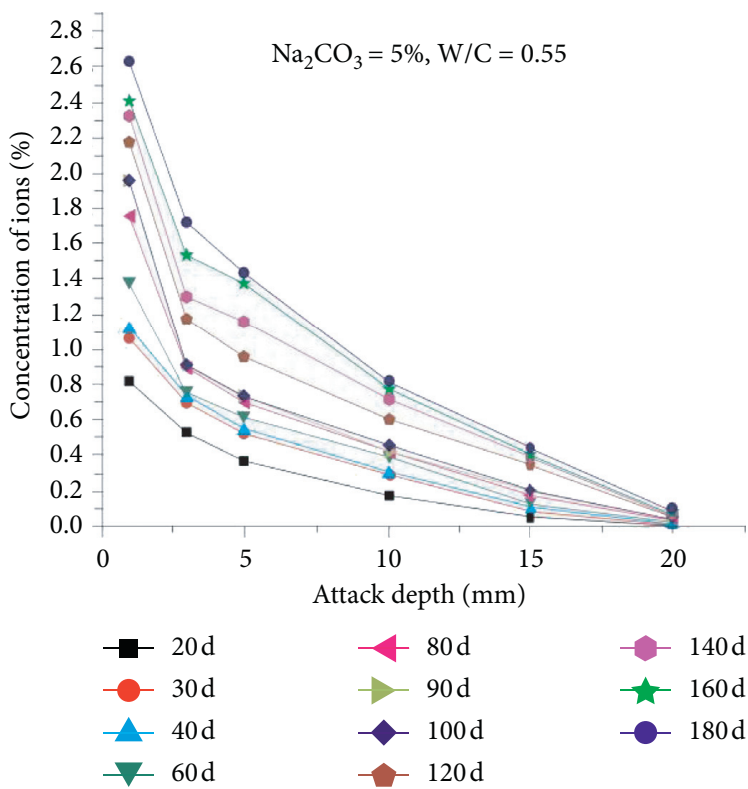

(c)

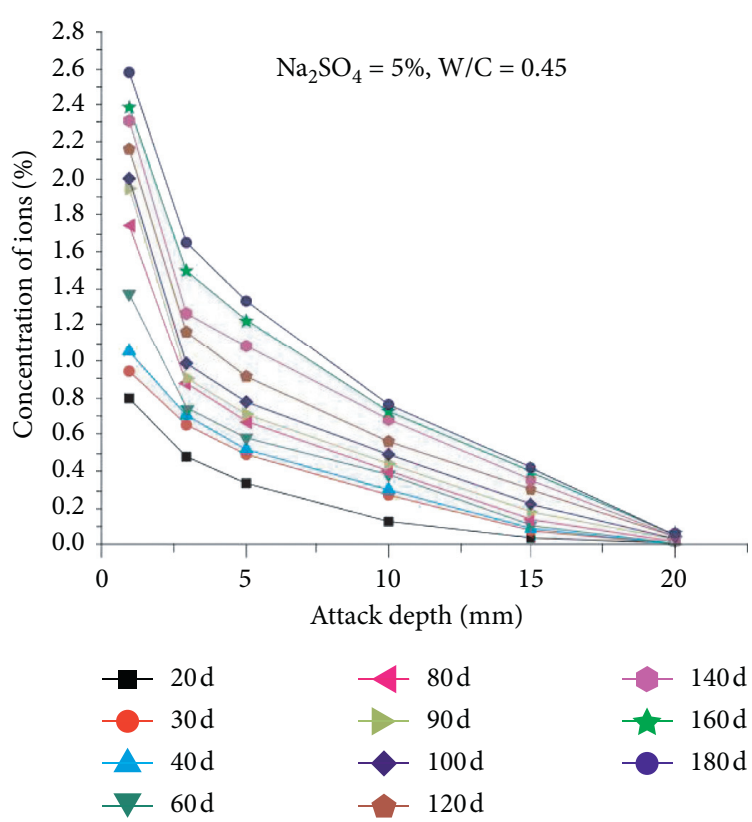

(b)

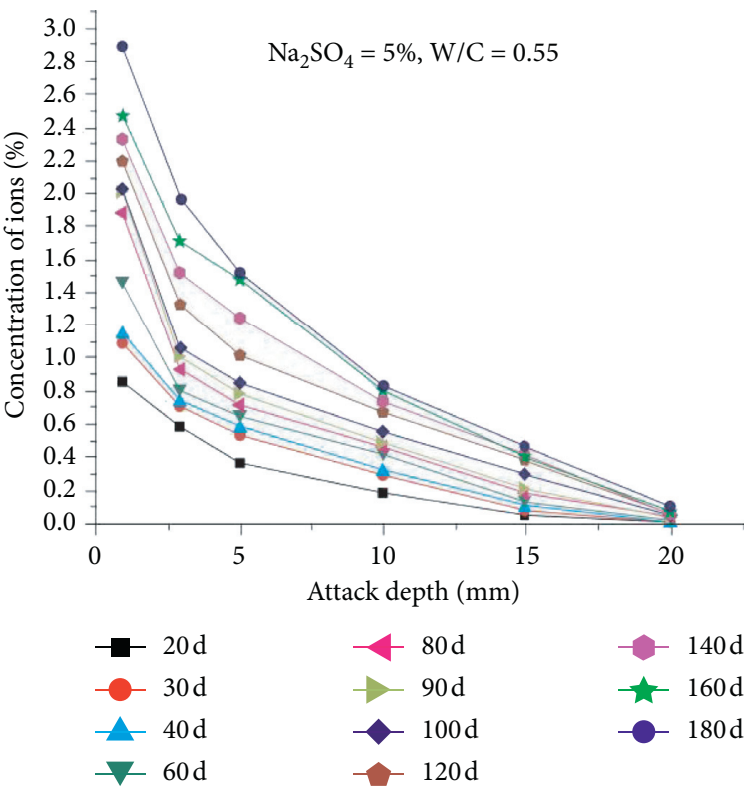

(d)

FIgURE 6: Relationship between the test results of ion content in different attack depths of concrete and varied cycles 4.

The points in Figure 7 are drawn referring to experiment data, and the curves are drawn according to equations (11)-(14). Figure 7 illustrates the relationship between varied drying-wetting cycles and the concentration of ions when setting the times of drying-wetting cycle as abscissa and setting the concentration of ions in the convection and diffusion regions of concrete as ordinate. Photos of SEM at 180 days are also provided to reflect the percent of pores and the microstructure of pores in different regions of concrete.

We drew the following conclusions:

(1) The water-cement ratio affects the transportation channels in concrete by influencing the pores in concrete. The microstructure in concrete shown in the SEM images in Figure 7 implies that higher water-cement ratio makes microstructure porous and vice versa the microstructure appears dense, and these ions are easier to attack when the times of drying-wetting cycle, carbonate-ion and sulfate-ion attack depth, and ion category are similar. As the water-cement ratio increases, the $P$ value becomes bigger. Apart from these conclusions, the concentration of ions in concrete with water-cement ratio of 0.55 is higher than that in concrete with the watercement ratio of 0.45 . The concentration of sulfate ion in concrete whose water-cement ratio is 0.55 is $8.98 \%$ 


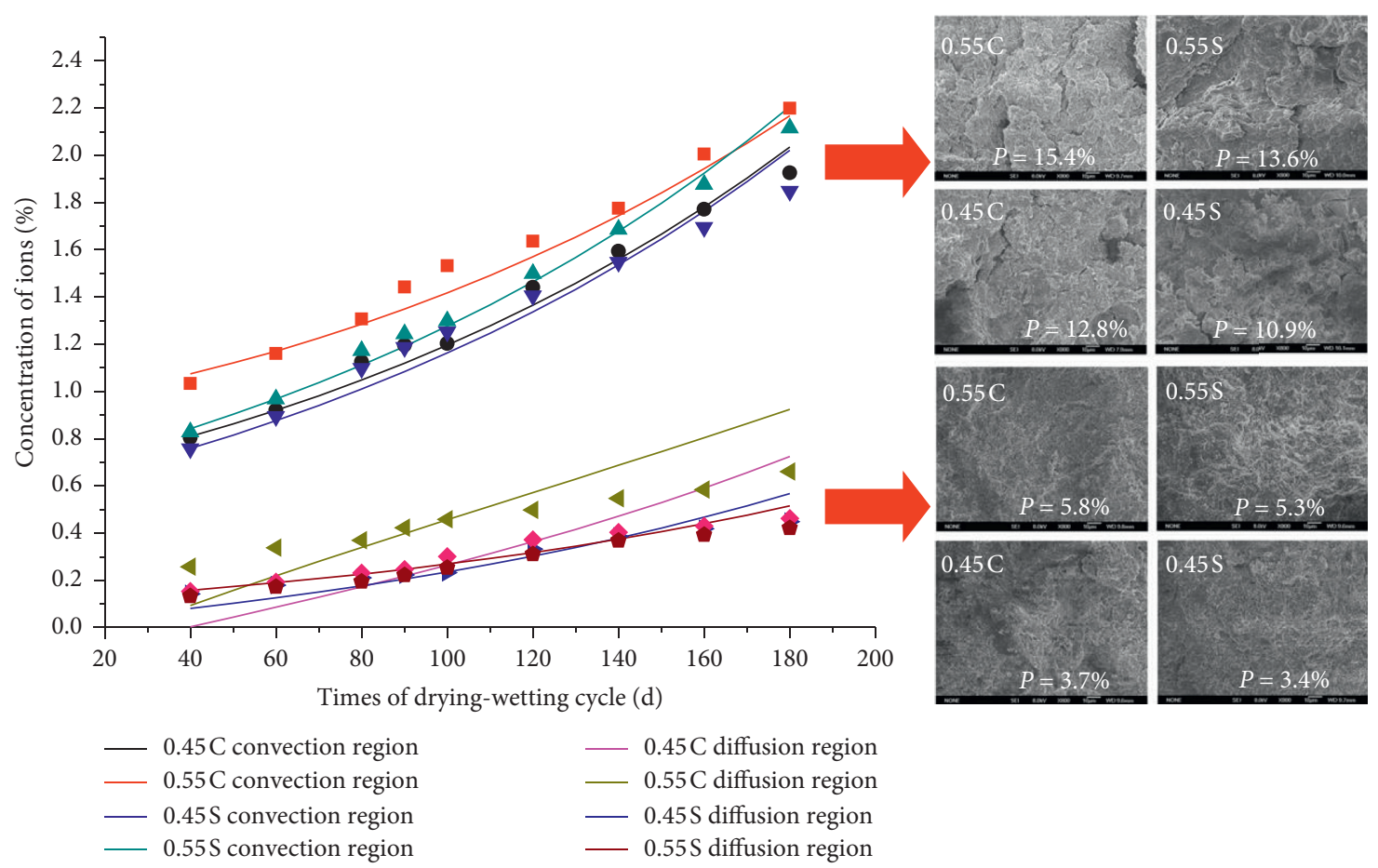

FIGURE 7: Relationship between the concentration of ions and the times of drying-wetting cycle and relative region microstructure photos of SEM.8.

higher than that in concrete whose water-cement ratio is 0.45 . The concentration of carbonate ion in concrete whose water-cement ratio is $20.2 \%$ higher than that in concrete with water-cement ratio of 0.45 .

(2) Results vary when the concrete specimen suffer from carbonate ion attack and sulfate ion attack. The corrosion effect of carbonate ion is more serious than that of sulfate ion when the water-cement ratio and the times of drying-wetting cycle of concrete are the same. The carbonate ion content is higher than sulfate ion content regardless of the experiment result or calculated result. The content of carbonate ion is $14.2 \%$ higher than that of sulfate ion in concrete whose water-cement ratio is 0.55 . Likewise, the content of carbonate ion is $3.52 \%$ higher than that of sulfate ion in concrete whose water-cement ratio is 0.45 .

(3) Sizable distance exists between two kinds of ions in the convection and diffusion regions of concrete, and the ion content in convection region is clearly more than that in diffusion region. We concluded the laws of ions attack depth of carbonate ion and sulfate ion according to the experiment result in Figure 6. The carbonate ion and sulfate ion attack depth were limited at specified drying-wetting cycle; the ion content almost reached 0 at $20 \mathrm{~mm}$ attack depth, and the ion content dropped rapidly at $5 \mathrm{~mm}$ attack depth. The results verify the rationality of dividing the concrete into two compartments.

(4) The experiment data were uniformly distributed between relative color curves. The calculated values of $120,140,160$, and 180 days were verified by experiment results, and the difference is within the accepted range such that the calculation results of the two-compartment model were built through shortterm experiment data $(40,60,80$, and 100 days) which were verified by long-term experiment results (120, 140, 160, and 180 days), thus verifying the reliability of model prediction consequence. The two-compartment model can dynamically and accurately describe the carbonate and sulfate ions content in different regions of concrete at varied drying-wetting cycles, and it can also predict the ions content at long-term cycles.

\section{Conclusions}

In this paper, the classic compartment model in pharmacokinetics was introduced to dynamically describe the transportation of carbonate and sulfate ions. The following conclusions were drawn on the basis of both theoretical analyses and experimental works:

(1) Based on the similarity between the transportation of carbonate and sulfate ions in concrete under the drying-wetting cycle environment and the ingression and elimination of medicine in human body, a twocompartment model was established from the knowledge of differential equation and the analytical expression in which the model was acquired. The reliability of model was verified by combining the short-term experiment data.

(2) Factors, including water-cement ratio, ion attack depth, times of drying-wetting cycle, and ion category, were considered in the model establishment 
and solution. Thus, the analytical expression of compartment model can dynamically describe the ion content in different ion attack depths of concrete at varied drying-wetting cycles.

(3) The calculation results of the two-compartment model supported by short-term experiment data were verified by long-term experiment results. This model can predict long-term ion content in concrete at the specified drying-wetting cycle, and the consequences of prediction match the experiment data well. This model is important for research on durability and protection of concrete in carbonate-rich and sulfate-rich environment.

\section{Data Availability}

All data generated or analyzed during this study are included in this published article.

\section{Conflicts of Interest}

The authors declare that they have no conflicts of interest.

\section{Acknowledgments}

This work was financially supported by the State Key Program of the National Natural Science Foundation of China (Grant no. 41430642), the Special Fund for Major Scientific Instruments of the National Natural Science Foundation of China (Grant no. 41627801), and the China Postdoctoral Science Foundation (Grant no. 2015M581403).

\section{References}

[1] G. d. Vera, M. A. Climent, E. Viqueira et al., "Chloride penetration prediction in concrete through an empirical model based on constant flux diffusion," Journal of Materials in Civil Engineering, vol. 27, no. 8, Article ID 04014231, 2015.

[2] W. Jin, Y. Yan, and H. Wang, "Research progress on the chloride transportation in stressed concrete," Journal of the Chinese Ceramic Society, vol. 38, no. 11, pp. 2217-2224, 2010.

[3] W. Jin, L. Jin, Y. Yan et al., "Field inspection on chloride ionintrusion effect of seawater in dry-wet cycling zone of concrete structures," Journal of Hydraulic Engineering, vol. 40, no. 3, pp. 364-371, 2009.

[4] Y. Zhou, D. Niu, and J. Wang, "Experimental research on chloride ion erosion of shotcrete in the marine underwater area," Concrete, vol. 12, pp. 14-17, 2014.

[5] C. Yuan, D. Niu, and G. Qi, "Diffusion of chloride ions into concrete under joint action of carbonation and salt spray," Journal of Jiangsu University (Natural Science Edition), vol. 34, no. 5, pp. 605-609, 2013.

[6] H. He, R. Li, and K. Chen, "Durability evolution of RC bridge under coupling action of chloride corrosion and carbonization based on DLA model," Mathematical Problems in Engineering, vol. 2015, Article ID 951846, 11 pages, 2015.

[7] Y. Zhang, H. Zhuang, J. Shi, J. Huang, and J. Zhang, "Timedependent characteristic and similarity of chloride diffusivity in concrete," Magazine of Concrete Research, vol. 70, no. 3, pp. 129-137, 2018.

[8] Z. Hu, L.-X. Mao, J. Xia et al., "Five-phase modelling for effective diffusion coefficient of chlorides in recycled concrete," Magazine of Concrete Research, vol. 70, no. 11, pp. 583-594, 2018.

[9] Y. Yan, W. Jin, and H. Wang, "Chloride ingression in cracked concrete under saturated state," Journal of Zhejiang University (Engineering Science), vol. 45, no. 12, pp. 2127-2133, 2011.

[10] Y. Yan, W. Jin, H. Wang et al., "Chloride transport in cracked concrete under wet-dry cycling condition," Journal of Central South University (Science and Technology), vol. 44, no. 5, pp. 2060-2067, 2013.

[11] Z. Liu, W. Chen, Y. Zhang, and H. Lv, "A three-dimensional multi-scale method to simulate the ion transport behavior of cement-based materials," Construction and Building Materials, vol. 120, pp. 494-503, 2016.

[12] G. Sun, W. Sun, Y. Zhang et al., "Predicting effective chloride ion diffusion coefficient in cement-based composite materials," Journal of Southeast University (Natural Science Edition), vol. 41, no. 2, pp. 376-381, 2011.

[13] G. Sun, W. Sun, Y. Zhang et al., "A multi-scale prediction of effective diffusion coefficient of chloride ion in hardened cement paste," Journal of Jiangsu University (Natural Science Edition), vol. 32, no. 4, pp. 468-473, 2011.

[14] G. Sun, W. Sun, Y. Zhang, and Z. Liu, "Multi-scale modeling of the effective chloride ion diffusion coefficient in cementbased composite materials," Journal Wuhan University of Technology Materials Science Edition, vol. 27, no. 2, pp. 364-373, 2012.

[15] L. Gao, G. Sun, Y. Zhang et al., "Relationship between porosity and chloride diffusivity in cement-based composite materials," Journal of Chongqing University, vol. 35, no. 11, pp. 53-61, 2012.

[16] O. P. Kari, Y. Elakneswaran, T. Nawa, and J. Puttonen, “A model for a long-term diffusion of multispecies in concrete based on ion-cement-hydrate interaction," Journal of Materials Science, vol. 48, no. 12, pp. 4243-4259, 2013.

[17] W. Lin, C. Liu, and M. Li, "Influences of specific ions in groundwater on concrete degradation in subsurface engineered barrier system," SpringerPlus, vol. 5, p. 18, 2016.

[18] B. Bary, N. Leterrier, E. Deville, and P. Le Bescop, "Coupled chemo-transport-mechanical modelling and numerical simulation of external sulfate attack in mortar," Cement and Concrete Composites, vol. 49, pp. 70-83, 2014.

[19] J. Cao, Y. Wang, K. Li, and Y. Ma, "Modeling the diffusion of chloride ion in concrete using cellular automaton," Journal of Materials in Civil Engineering, vol. 24, no. 6, pp. 783-788, 2012.

[20] X. Zhang, W. Qing, G. Wang et al., “A study on the coupled model of hydrothermal-salt for saturated freezing salinized soil," Mathematical Problems in Engineering, vol. 2017, Article ID 4918461, 12 pages, 2017.

[21] G. Wang, Pharmacokinetics, Chemical Industry Press, Beijing, China, 2005.

[22] The European Union-Brite EuRam, BE95-1347 General Guide Lines for Durability Design and Redesign, The European Union-Brite EuRam III, Bruxelles, Belgium, 2000.

[23] H. Tian, Y. Zhou, L. Sui, and F. Xing, "Evolution of the sulfate ion transport-deterioration process in concrete," Anti-Corrosion Methods and Materials, vol. 63, no. 3, pp. 196-204, 2016.

[24] J. Ozbolt, F. Orsanic, and G. Balabanic, "Modeling influence of hysteretic moisture behavior on distribution of chlorides in concrete," Cement and Concrete Composites, vol. 67, pp. 7384, 2016.

[25] Q. Jiang, J. Xie, and J. Ye, Mathematical Model, Higher Education Press, Beijing, China, 2011. 
[26] M. Nasir, M. A. Johari, M. Maslehuddin, and M. Yusuf, "Sodium sulfate resistance of alkali/slag activated silicomanganese fume-based composites," Structural Concrete, vol. 79, pp. 1-15, 2020.

[27] M. Nasir, M. A. Johari, M. Maslehuddin, and M. Yusuf, "Sulfuric acid resistance of alkali/slag activated silico-manganese fume-based mortars," Structural Concrete, vol. 543, pp. 1-15, 2020.

[28] ASTM C1894-19 Standard Guide for Microbially Induced Corrosion of Concrete Products.

[29] ASTM C114-18 Standard Test Methods for Chemical Analysis of Hydraulic Cement.

[30] M. Nasir, M. A. Johari, M. Maslehuddin, M. Yusuf, and M. AlHarthi, "Influence of heat curing period and temperature on the strength of silico-manganese fume-blast furnace slagbased alkali-activated mortar," Construction and Building Materials, vol. 251, 2020. 